\title{
Design of New Barrier Outperformance Certificates in Oil Market
}

\author{
Vincent Soltes, Monika Harcarikova
}

\author{
Technical University of Kosice \\ Nemcovej 32, 04001 Kosice, Slovakia \\ E-mail.vincent.soltes@tuke.sk,monika.harcarikova@tuke.sk \\ cross $^{\text {ref }}$ http://dx.doi.org/10.5755/j01.ee.28.3.11481
}

\begin{abstract}
This paper proposes new innovative financial instruments in oil market. Modifications of outperformance certificates with barrier, i.e. barrier reverse outperformance and barrier reverse outperformance certificates with cap have a significant place in the segment of partial guaranteed investment tools due to a security buffer. These modifications of outperformance certificates with barrier are designed with the aim to make a disproportionately higher profit in bear market. Certificates' profit functions provided in an analytical form are described in detail. It has been proved that the certificates' profit functions are designed using two groups of instruments, i.e. an underlying asset and a financial derivative on its underlying instrument, especially American vanilla and barrier options. Financial engineering principles are explored to the investment certificates creation using the analytical expression of the American-style of vanilla and barrier call/put options. Pricing formulas are developed for these certificates with a specification of the conditions for the issuer in the primary market with the aim to achieve a profit. Then some investment certificates for these categories of innovative products connected with the United States Brent Oil ETF on $1^{\text {st }}$ December 2014 are created, analysed and compared to each other. Also, the investor's best results at the future trade date are revealed. Our approach is based on real-traded American vanilla options data gained from Bloomberg. Due to lack of real-traded barrier options, the barrier option premiums are processed with Haug option pricing model in Bloomberg. The main aim is to prove the nature of barrier reverse outperformance certificates' creation and their cap modification with the increasing of the intellectualization of all potential investors.
\end{abstract}

Keywords: Barrier Reverse Outperformance Certificate, Capped Barrier Reverse Outperformance Certificate, Vanilla Options, Barrier Options, Option Pricing.

\section{Introduction}

Today investment certificate's market is widened and a lot of commercial and investment banks offer various types of these innovative products. Investment products (referred to as structured investments) have a significant place in the structured products' segment. In recent years, there have been plenty of studies such as Bluemke (2009) or Choudhry (2004) that introduce these modern structured products.

New modified outperformance certificates with the barrier, belonging to one type of the structured products, are the object of this research. The paper' $s$ main purpose is to introduce and analyse new type of outperformance certificates with the barrier, i.e. barrier reverse outperformance certificates and their modification with cap. However, the paper's research problem is to demonstrate the nature of these products' design through the financial engineering, i.e. mainly using options and option strategies, with finding who profits from these products. Our research is applied in oil market. The proposed investment certificates can offer a fascinating overview of the financial innovation with an ability to take a position in different markets and asset classes as commodities, interest rates, foreign currencies, indices, shares or basket of shares. Despite of this, market trends influence the financial innovation process. At first, it is necessary to present the background of these products using literature review so that we could continue in our research.

According to Swiss Structured Products Association (SSPA), structured products contain two main components as the underlying asset (to be referred to as UA henceforth) together with the derivative tool, mainly an option component (combination of plain-vanilla and barrier option). Investment with limited costs to the underlying assets, such as company's shares, basket of shares, indices, currencies or different types of commodities, are offered by investment certificates. We can meet with different risk/return profiles, which allow the investors to find a product most suited to his/her risk propensity at the prevailing market conditions. Due to their flexibility in adapting to new UA, they are ideal instruments for optimising portfolios. Breuer and Perst (2007) and Das and Statman (2013) have studied the structured products' role in behavioural portfolios. Benet et al. (2006) have focused on part of structured products, specifically reverseexchangeable securities, where the replication methods are used in these products pricing. Speculating and investing in leverage structured products from the retail investor's point of view are introduced by Schroff et al. (2016). On the other hand, the case of multi-asset barrier reverse convertibles in the Switzerland market is researched by Wallmeier and Diethelm (2009). Investment certificates represent the biggest part of structured products. Thus, issuers (mainly the banks) are continuously offering new 
types of these products. Although many private investors feel that the investment in certificates is particularly highrisk, it is not always the truth. The new type of the bonus certificates using vanilla and barrier options is proposed by Younis and Rusnakova (2014). For example, Gordiakova and Younis (2013), Hernandez et al. (2011), Hernandez et al. (2014) and Rusnakova et al. (2014) examine selected investment certificates such as guarantee, protect and bonus certificates. The given products' creation using selected option strategies is researched by Soltes (2012) and Soltes (2011). Rossetto and Bommel (2009) have analysed endless leverage certificates using Monte Carlo method. Also, Entrop et al. (2009) have presented the price-setting formula for open-end leverage certificates on the German market.

The basic part of every introduced certificate is option component. Geman (2005) defines option as a financial contract giving its holder (the owner or the buyer) the right (on the other side not the obligation) to buy (call) or sell (put) UA at a specified price (the strike or the exercise price) of the option on a specified date (either at the expiration date of option - European style or at any time within a specified option expiration period - American style). The call/put option seller (the writer) receives the option premium for buyer's right. Exotic options introduce new generation of options with a widely used class of barrier options. The barrier level (also known as the second strike price) is typical for barrier options. According to Taleb (1997), there are total 16 types of barrier options that depend on the activation/deactivation of options (in/out option) and the placement of the barrier level (up/down option). The methodology of our research is based on the option strategies' analytical expression of profit functions. The analytical form of selected options and option strategies used on structured products creation were discussed by Soltes (2002). The optimal algorithm for the using of different selected option strategies was analysed by Soltes (2001). Barrier options can be also used on hedging, i.e. the risk management against unfavourable price movement. Tauser and Cajka (2014) have dealt with the commodity risk management. Rusnakova and Soltes (2012) have analysed Long Strangle strategy and Soltes and Rusnakova, (2012; 2013) have introduced Long Combo and Inverse Vertical Ratio Put Spread strategy using barrier options, all for hedging against a price drop. Also descriptions of plain-vanilla and higher level of barrier options are introduced in detail by Hull (2012) and Zhang (1998).

On the basis of existing studies we can explore the financial engineering principles to the capped/barrier reverse outperformance certificates creation using the analytical expression of the options. Our empirical research is based on real data of American vanilla options from $1^{\text {st }}$ December 2014 (Bloomberg). There is also Haug pricing model used to evaluate the barrier option prices in Bloomberg database due to lack of real data. Presented option pricing models are used for determination of pricing formulas to our designed certificates. The basic parameters are investigated in a sensitivity analysis of the certificates' price. Consequently, several certificates on the United States Brent Oil ETF using different factors are created, compared and analysed with the aim to investigate the investor's profitability. The paper's main purpose is to show the creation of our designed certificates with the application in oil market. Our approach, based on the proposed investment certificates, can be provided as an inspiration for the creation of further types of these financial innovations. Our findings could be useful to investment certificates' issuers who are willing to increase the level of their products' transparency. The findings should help to increase the investors' ability to understand these innovative instrument's creation. The investors are able to make the best investment decisions in the future according to the expectations of UA's price performance. This approach is robust for various financial asset classes, such as a commodity, shares, indices or foreign currency, the use of which may be widened in the scientific and the commercial area.

The remaining part of the paper is organized as follows. Part one presents new outperformance certificates with the barrier, i.e. barrier reverse outperformance certificates and their cap modification. The next part introduces the methodology used in the paper based on the pricing models of the certificates. The following part proposes the application of our approach on the United States Brent Oil ETF, where investment certificates are created and compared using different factors based on real data from $1^{\text {st }}$ December 2014. The paper is concluded in the last part.

\section{Analysis of New Outperformance Certificates with the Barrier}

The paper focuses on the modifications of outperformance certificates, i.e. barrier reverse outperformance (to be referred to as BROC henceforth) and capped barrier reverse outperformance certificates (to be referred to as CBROC henceforth). These new products are only designed for bear markets with provided detailed analysis. Hernandez et al. (2013) have investigated the classic outperformance certificate. Its modification sprint certificate is analysed by Soltes (2010). Classic reverse outperformance certificate in agricultural market is proposed by Harcarikova (2015). More comprehensive analysis of our designed new outperformance certificates with barrier is realized based on the following studies mentioned.

Presented new outperformance certificates, i.e. BROC and CBROC belong to the group of the partial guaranteed investment instruments. These certificates enable investors to participate disproportionately on the UA's price drop. However, capped certificates are limited with the cap level. The leverage (or the participation rate) is higher than 100 $\%$. Thus, the probability of making a higher profit is secured to the investor in comparison to investing directly to UA. The disproportionate yield is not related on the other hand with the higher risk. In relation to the UA's price increases, the upper barrier level, introduced the security buffer, is set. As with any investment, investors in all reverse certificates have to be aware of the potential risks involved. In extreme cases, the threat of total investment loss is possible only for case if the UA's price increases above twice of the actual spot price. Our designed outperformance certificates are suitable mainly 
for bear market, which is connected with the security buffer for the UA's growth.

Barrier reverse outperformance certificate is a reverse outperformance certificate's modification connected with the partial capital protection, i.e. security buffer, for case of unfavourable UA's price performance. This instrument offers the investors an interesting investment opportunities for bear markets. Four possible payoffs at the expiration date are offered. The lower UA's price at the expiration than the actual spot price causes participating disproportionately in the reverse UA's performance due to the leverage. A partial risk protection is represented by the barrier level, which is set above the actual UA's spot price. If UA's price at any time before the expiration (American-style) or at the expiration date (European-style) touches the barrier level, the partial protection is cancelled and BROC changes into a classic reverse outperformance certificate. According to the actual spot price, the inversely participation in UA's positive performance is offered to the investor. If UA's price is higher than twice of the actual UA's spot price, the investor suffers a total investment loss. Given certificate is mainly suitable when strongly falling prices in the market or slightly increasing up to the barrier level are expected. Harčarikova (2015) have introduced the profit function of classic reverse outperformance certificate. Based on this function, given certificate with the barrier level is divided.

Analytical expression of BROC's profit function is derived by the following relation:

$$
P\left(S_{T}\right)= \begin{cases}p m\left(S_{0}-S_{T}\right)+p S_{0}-k_{0} & \text { if } S_{T}<S_{0} \\ p S_{0}-k_{0} & \text { if } \max _{0 \leq t \leq T}\left(S_{t}\right)<B \wedge S_{T} \geq S_{0} \\ p\left(S_{0}-S_{T}\right)+p S_{0}-k_{0} & \text { if } \max _{0 \leq t \leq T}\left(S_{t}\right) \geq B \wedge S_{T}<2 S_{0} \\ -k_{0} & \text { if } S_{T} \geq 2 S_{0}\end{cases}
$$

where $S_{0}$ is the actual spot price, $S_{T}$ is the price at the expiration date, $B$ is the barrier, $p$ is the multiplier, $m$ is the leverage, $t$ is the time to maturity, $T$ is the expiration date and $k_{0}$ is the certificate's buying price.

BROC's profit function (1) is the same as the profit function of the alternative investment portfolio, which is created as a combination of the following positions:

- $\quad$ the selling of $p$ UA with the actual spot price $S_{0}$ and the price at the expiration date $S_{T}$

$$
P_{I}\left(S_{T}\right)=p\left(S_{0}-S_{T}\right),
$$

- $\quad$ the buying of $p \cdot(m-1)$ put options on UA with the strike level equals the actual spot price $S_{0}$, the premium $p_{B}$ for an option and the expiration date $T$

$$
P_{2}\left(S_{T}\right)= \begin{cases}-p(m-1)\left(S_{T}-S_{0}+p_{B}\right) & \text { if } S_{T}<S_{0}, \\ -p(m-1) p_{B} & \text { if } S_{T} \geq S_{0},\end{cases}
$$

- $\quad$ the buying of $p$ up-and-out call options on UA with the strike level equals the actual spot price $S_{0}$, the barrier level $B$, the premium $c_{B U O}$ for an option, the expiration date $T$ and the same time to option's expiration $t$ and the time to certificate's expiration $t$

$$
P_{3}\left(S_{T}\right)= \begin{cases}-p c_{B U O} & \text { if } S_{T}<S_{0}, \\ p\left(S_{T}-S_{0}-c_{B U O}\right) & \text { if } \max _{0 \leq t \leq T}\left(S_{t}\right)<B \wedge S_{T} \geq S_{0}, \\ -p c_{B U O} & \text { if } \max _{0 \leq t \leq T}\left(S_{t}\right) \geq B \wedge S_{T} \geq S_{0},\end{cases}
$$

- the buying of $p$ call options on UA with the strike level equals 2 the actual spot price $2 S_{0}$, the premium $c_{B}$ for an option and the expiration date $T$

$$
P_{4}\left(S_{T}\right)= \begin{cases}-p c_{B} & \text { if } S_{T}<2 S_{0}, \\ p\left(S_{T}-2 S_{0}-c_{B}\right) & \text { if } S_{T} \geq 2 S_{0} .\end{cases}
$$

Modified option analytical expressions of the relations (2), (3) and (5) are introduced by Harčarikova (2015) and modified relation (4) is shown by Bobrikova and Harčarikova (2015).

The alternative investment's profit function introduced as a sum of individual positions (2), (3), (4) and (5) has a form:

$$
P\left(S_{T}\right)= \begin{cases}p m\left(S_{0}-S_{T}\right)-p\left((m-1) p_{B}+c_{B U O}+c_{B}\right) & \text { if } S_{T}<S_{0}, \\ -p\left((m-1) p_{B}+c_{B U O}+c_{B}\right) & \text { if } \max _{0 \leq t T}\left(S_{t}\right)<B \wedge S_{T} \geq S_{0}, \\ p\left(S_{0}-S_{T}\right)-p\left((m-1) p_{B}+c_{B U O}+c_{B}\right) & \text { if } \max _{0 \leq t T}\left(S_{t}\right) \geq B \wedge S_{T}<2 S_{0}, \\ -p\left(S_{0}+(m-1) p_{B}+c_{B U O}+c_{B}\right) & \text { if } S_{T} \geq 2 S_{0} .\end{cases}
$$

Using alternative form of investment (6), there is derived identical profit function as BROC's profit function (1) only for case if the certificate's fair value

$$
k_{O}=p\left(S_{O}+(m-1) p_{B}+c_{B U O}+c_{B}\right)
$$
is met.

Certificate's issuer can obtain a profit only if the selling certificate's price is above the fair value $k_{0}$, i.e. $k_{0} \geq p\left(S_{O}+(m-1) p_{B}+c_{B U O}+c_{B}\right)$.

\section{Capped Barrier Reverse Outperformance Certificate}

This certificate is a modification of BROC with partially limited disproportional participation in the UA's price drop only up to the cap. The cap represents the maximum limitation on the certificate's performance in the bear trend of UA and is always placed below the actual UA's spot price. Using of this certificate's type is mainly when UA's price is slightly falling or slightly increasing up to the barrier level. Given certificate generally contains the higher participation rate than BROC due to the cap level.

Analytical expression of CBROC's profit function is derived following relation:

$$
P\left(S_{T}\right)= \begin{cases}p m\left(S_{0}-C\right)+p S_{0}-k_{0} & \text { if } S_{T}<C, \\ p m\left(S_{0}-S_{T}\right)+p S_{0}-k_{0} & \text { if } C \leq S_{T}<S_{0}, \\ p S_{0}-k_{0} & \text { if } \max _{0 \leq t \leq T}\left(S_{t}\right)<B \wedge S_{T} \geq S_{0}, \\ p\left(S_{0}-S_{T}\right)+p S_{0}-k_{0} & \text { if } \max _{0 \leq t \leq T}\left(S_{t}\right) \geq B \wedge S_{T}<2 S_{0}, \\ -k_{0} & \text { if } S_{T} \geq 2 S_{0},\end{cases}
$$

where $S_{0}$ is the actual spot price, $S_{T}$ is the price at the expiration date, $B$ is the barrier, $C$ is the cap level, $p$ is the multiplier, $m$ is the leverage, $t$ is the time to expiration, $T$ is the expiration date and $k_{0}$ is the certificate's buying price.

CBROC's profit function (8) is the same as the profit function of the alternative investment portfolio using positions (2), (3), (4), (5) and

- $\quad$ by buying of $p \cdot m$ put options on UA with the strike level equals the cap level $C$, the premium $p_{S}$ for an option and the expiration date $T$

$$
P_{5}\left(S_{T}\right)= \begin{cases}p m\left(S_{T}-C+p_{S}\right) & \text { if } S_{T}<C, \\ \text { pmp }_{S} & \text { if } S_{T} \geq C .\end{cases}
$$

Modified option analytical expression of the relation (9) is introduced by Harčarikova (2015). 
CBROC is created without initial costs only if the following condition

$$
m p_{S}=(m-1) p_{B}+c_{B U O}+c_{B}
$$

is met. However, the option premium $p_{S}$ should be sufficiently large. Generally, the higher put option premium is connected with the higher strike price and vice versa. The higher profit's multiplicity is connected with the higher cap level, which should be set closer to the actual spot price.

The alternative investment's profit function may be interpreted as a sum of individual positions (2), (3), (4), (5) and (9) has a form:

$$
P\left(S_{T}\right)= \begin{cases}p m\left(S_{0}-C\right)+p\left(m\left(p_{S}-p_{B}\right)+p_{B}-c_{B U O}-c_{B}\right) & \text { if } S_{T}<S_{0}, \\ p m\left(S_{0}-S_{T}\right)+p\left(m\left(p_{S}-p_{B}\right)+p_{B}-c_{B U O}-c_{B}\right) & \text { if } S_{T}<S_{0}, \\ p\left(m\left(p_{S}-p_{B}\right)+p_{B}-c_{B U O}-c_{B}\right) & \text { if } \max _{0 \leq \leqslant T}\left(S_{t}\right)<\mathrm{B} \wedge \mathrm{S}_{\mathrm{T}} \geq S_{0}, \\ p\left(S_{0}-S_{T}\right)+p\left(m\left(p_{S}-p_{B}\right)+p_{B}-c_{B U O}-c_{B}\right) & \text { if } \max _{0 \leq \leqslant T}\left(S_{t}\right) \geq \mathrm{B} \wedge \mathrm{S}_{\mathrm{T}}<2 S_{0}, \\ -p\left(S_{0}-m\left(p_{S}-p_{B}\right)-p_{B}+c_{B U O}+c_{B}\right) & \text { if } S_{T} \geq 2 S_{0} .\end{cases}
$$

If the formula

$$
k_{0}=p\left(S_{0}-m\left(p_{S}-p_{B}\right)-p_{B}+c_{B U O}+c_{B}\right)
$$

and the equation (10) is fulfilled, then the alternative portfolio's profit function (11) is identical to the presented certificate's profit function (8). Certificate's issuer can obtain a profit only if the selling certificate's price is above the fair value (12).

\section{Research Methodology}

Generally, investment certificates are created as the combination of UA and the financial derivatives, mainly options and option strategies on this UA. Options introduce the significant tool of every investment certificates, therefore the methodology used in this paper should be based on these instruments. There is proved the nature of barrier reverse outperformance certificates' creation and their modification with cap using the analytical expression of the profit functions of classic vanilla and barrier options. According to the presented research, we can simultaneously design further investment certificates.

The fair value of every investment certificate can be calculated based on the individual components' value, i.e. an alternative portfolio's value created as the position in UA together with options. The issue of the structured products valuation is discussed by Burth et al. (2001), Henderson and Pearson (2011) and Wilkens et al. (2003). The pricing of equity-linked structured products in the German market is examined by Stoimenov and Wilkens (2005). Grunbichler and Wohlwend (2005) analyses structured products valuation without a capital guarantee in the Swiss market. The pricing of bonus certificates is investigated by Baule and Tallau (2011). Wilkens and Stoimenov (2007) describe the empirical analysis for long and short index certificates pricing in the German market. And Hernandez et al. (2013) provide the valuation of outperformance certificates.

Every investment certificate can be evaluated using option pricing models according to its UA. Based on the alternative portfolio's value, the fair value of BROC is expressed by the equation (7) and CBROC is expressed by (12).
Firstly, the values of the vanilla and barrier positions are needed to obtain. Black and Scholes (1973) introduced theoretical price of European vanilla call and put options on the stocks without dividends. Merton (1973) modified Black-Scholes formula, where he considered the pricing of vanilla call and put options on the stocks with dividends. Garman and Kohlhagen (1983) extended the BlackScholes model on currency options. Later Black (1976) evaluated European futures options, which can be applied on all commodities. In practice, American-style of options on futures are traded on the CME Group (CME) and the Chicago Board Options Exchange (CBOE). Also, American-style of option prices are the higher than the European-style of option prices due to possibility of early redemption. Ramaswamy and Sundaresan (1985) dealt with American vanilla options valuation on futures contracts. Valuation of the barrier options is influenced by next factor, i.e. the barrier level. Therefore, Merton (1973) modified Black-Scholes model with a derivation of the first relationship for European down and knock-out call option price. Later Rubinstein and Reiner (1991) applied Black-Sholes-Merton formula on 8 basic types of barrier options and Haug (1997) on all 16 types of standard European barrier options. Finally, a mathematical structure of barrier options value was derived by Rich (1997). Nishiba (2013) dealt with the new method for pricing exotic options. Numerical methods for theoretical price of American barrier options are introduced by Boyle and Lau (1994), Haug (1999) and Ritchken (1994).

For the aims of our analysis, there are used real American vanilla call and put option prices gained from Bloomberg. Due to the lack of market barrier option data, American-style of up and knock-out call barrier options are calculated with the implementation in Bloomberg database.

\section{Application on Brent Crude Oil}

Today oil market has seen the third largest dramatic decline from World War II due to the geopolitical conflicts in key oil regions as Libya, Iraq and Iran. Therefore, our application is focused on the United States Brent Oil ETF (to be referred to as BNO henceforth). It is a commodity ETF (exchange-traded fund), which is designed to track the daily price movements of Brent crude oil. BNO invests primarily in crude oil futures contracts with possibility to invest in forwards and swap contracts too. BNO is traded on the NYSE Arca. The price of BNO was around 46.00 USD in June 2014, but it had fallen to 30.00 USD in the end of November 2014. And right now, the price of Brent is still falling. Investment certificates on commodity ETFs are interesting alternative way for retail investors with making a profit in bull/bear markets without hold it in physical storage. Generally, energy commodities can be useful tools for creation of diversified investment portfolio. The focus of this paper is on the application for investment certificates on BNO. However, the results could be applied to any UA.

Let's assume, investors expect decline in oil market in future (up to July 2015) and want to gain from bear market. In this section, we propose BROC and CBROC on BNO. There are shown all parameters, on which the investors should pay attention when they decide to invest 
into these products. Then, an analysis of the investor's profitability is performed at the future trade date.

\section{Data Description}

The actual spot price of BNO is 28.61 USD on $1^{\text {st }}$ December 2014. We expect a falling within a half year or a year. We also believe the UA's value to remain under the pre-set barrier.

Our proposed certificates, suitable for our assumptions, are analysed and compared assume BNO option prices quotes on $1^{\text {st }}$ December 2014 (the issue date) with the expiration date $17^{\text {th }}$ July 2015 . There is traded American-style of vanilla options on BNO. All real American vanilla option prices and the implied volatilities $\left(\sigma_{\text {impl }}\right)$ are gained from Bloomberg, which we can find in the Table 1 .

Table 1

\section{Implied Volatilities (In \%) and American Call/Put Option Premiums on BNO (In USD) On 01/12/2014 with the Maturity Date 17/07/2015}

\begin{tabular}{|c|c|c|c|c|}
\hline \multicolumn{2}{|c|}{ CALL OPTION } & \multirow{2}{*}{ STRIKE } & \multicolumn{2}{|c|}{ PUT OPTION } \\
\cline { 1 - 1 } $\begin{array}{c}\boldsymbol{\sigma}_{\text {impl }} \\
(\boldsymbol{\%})\end{array}$ & $\begin{array}{c}\text { c (USD per } \\
\text { option) }\end{array}$ & (USD) & $\begin{array}{c}\text { p (USD per } \\
\text { option) }\end{array}$ & $\begin{array}{c}\boldsymbol{\sigma}_{\text {impl }} \\
(\boldsymbol{\%})\end{array}$ \\
\hline 31.67 & 5.45 & 24 & 0.95 & 31.58 \\
\hline 30.59 & 4.05 & 26 & 1.53 & 30.12 \\
\hline 28.45 & 2.49 & 28.61 & 2.62 & 28.45 \\
\hline 28.15 & 1.90 & 30 & 3.35 & 27.19 \\
\hline 33.84 & 0.01 & 57.22 & 28.49 & 33.84 \\
\hline
\end{tabular}

Source: Bloomberg

For calculation of up and knock-out call barrier option prices, we need the strike prices, the barrier levels, the cap levels, the expiration date, the risk-free interest rate and the implied volatilities. The barrier levels, the cap levels and the leverages are selected by the authors and specified at the time of issue. Generally, the lower barrier level is, the higher option premiums are and vice versa. American-style of barrier option prices is calculated for different barrier levels and strike prices in Bloomberg with the results in the Table 2.

Table 2

Calculated American Up and Knock-Out Call Option Premiums (USD per Option) on BNO on 01/12/2014 with the Maturity Date 17/07/2015

\begin{tabular}{|c|c|c|c|c|}
\hline \multirow{2}{*}{$\begin{array}{c}\text { (impl } \\
(\boldsymbol{\%})\end{array}$} & \multirow{2}{*}{$\begin{array}{l}\text { Strike } \\
\text { (USD) }\end{array}$} & \multicolumn{3}{|c|}{ Barrier (USD) } \\
\hline 30.59 & 26 & 3.38 & 3.87 & 3.99 \\
\hline 29.08 & 27 & 2.52 & 3.16 & 3.39 \\
\hline 28.45 & 28,61 & 1.26 & 2.15 & 2.46 \\
\hline 28.76 & 29 & 0.84 & 1.83 & 2.20 \\
\hline 28.15 & 30 & 0.00 & 1.21 & 1.70 \\
\hline
\end{tabular}

Source: own calculation in Bloomberg

The risk-free interest rate is the yield of government bond (at the level of $0.253 \%$ gained from Bloomberg) with similar expiration as the options. Due to simplifications, we assume transactions cost of 0 USD and the issue certificates' price equals to their fair value, i.e. the issuer's profit is zero.

\section{Analysis of Designed Certificates with Various Parameters}

Let's suppose with different levels of parameters, i.e. the barrier level $(32.00 ; 34.00)$, capped level $(26.00 ; 24.00)$ and the leverage $(2 ; 3)$. These parameters impact on the issue certificates' price and on the investor's profit too. The next common stylized data about the certificates we can see in the Table 3.

Table 3

Stylized Data about New Barrier Outperformance Certificates

\begin{tabular}{|c|c|}
\hline \multicolumn{2}{|c|}{ Key data } \\
\hline Underlying asset & United States Brent Oil ETF (BNO) \\
\hline Underlying price & 28.61 USD \\
\hline Issue date & $1^{\text {st }}$ December 2014 \\
\hline Expiration date & $17^{\text {th }}$ July 2015 \\
\hline Multiplier & $1: 1$ \\
\hline
\end{tabular}

Let us propose BROC as the replicating portfolio, i.e. the sum of BNO selling with the actual spot price 28.61 USD, the buying of put option in BNO with the strike level 28.61 USD, the leverage $200 \%$, i.e. $m=2$, option premium 2.62 USD for an option, the expiration date $17^{\text {th }}$ July 2015 , the buying of up and knock-out call option with the strike level 28.61 USD, the barrier level 32.00 USD, option premium 2.15 USD for an option, the expiration date $17^{\text {th }}$ July 2015 and the buying of call option in BNO with the strike level 57.22 USD, option premium 0.01 USD for an option, the expiration date $17^{\text {th }}$ July 2015 . The selling profit function of created BROC at the future trade date $t$ based on equation (6) and the certificate's buying price $k_{0}$ based on (7) equals 33.39 USD is shown by the form.

$$
P\left(S_{t}\right)= \begin{cases}52.44-2 S_{t} & \text { if } S_{t}<28.61, \\ -4.78 & \text { if } \max \left(S_{t}\right)<32.00 \wedge S_{t} \geq 28.61, \\ 23.83-S_{t} & \text { if } \max _{0 \leq t \leq T}\left(S_{t}\right) \geq 32.00 \wedge S_{t}<57.22, \\ -33.39 & \text { if } S_{t} \geq 57.22 .\end{cases}
$$

Now, let us propose CBROC as the sum of BNO selling with the actual spot price 28.61 USD, the selling of the higher amount of put option, where the strike level equals the cap level 26.00 USD, the leverage $200 \%$, i.e. $m=2$, option premium 1.53 USD for an option, the expiration date $17^{\text {th }}$ July 2015 , the buying of the lower amount of put option in BNO with the strike level 28.50 USD, the leverage $200 \%$, i.e. $m=2$, option premium 2.62 USD for an option, the expiration date $17^{\text {th }}$ July 2015 , the buying of up and knock-out call option with the strike level 28.61 USD, the barrier level 32.00 USD, option premium 2.15 USD for an option, the expiration date $17^{\text {th }}$ July 2015 and the buying of call option in BNO with the strike level 57.22 USD, option premium 0.01 USD for an option, the expiration date $17^{\text {th }}$ July 2015 . The selling profit function of created CBROC at the future trade date $t$ based on equation (11) and the certificate's buying price $k_{0}$ based on (12) equals 30.34 USD is

$$
P\left(S_{t}\right)= \begin{cases}3.49 & \text { if } S_{t}<26.00, \\ 55.49-2 S_{t} & \text { if } 26.00 \leq S_{t}<28.61, \\ -1.73 & \text { if } \max _{0 \leq t \leq T}\left(S_{t}\right)<32.00 \wedge S_{t} \geq 28.61, \\ 26.88-S_{t} & \text { if } \max _{0 \leq t \leq T}\left(S_{t}\right) \geq 32.00 \wedge S_{t}<57.22, \\ -30.34 & \text { if } S_{t} \geq 57.22 .\end{cases}
$$


Based on the comparison of above analysed certificates, the recommendations for the investors, which variant is the best according to their future expectations of the UA's price, are given. If they expect rapid drop, BROC is recommended, otherwise in case of slow drop, CRBOC is advantageous with the maximum profit of 3.49 USD per certificate.

The same method of profit profiles in the analytical expressions is used for next designed BROC and CBROC with different parameters. Data of all designed certificates are summarized in the Table 4 . Used profit profiles of all designed certificates at the future trade date can be provided readers upon a request.
Let's look at the influence of the given parameters (barrier level $B$, leverage $m$ and cap level $C$ ) on the change of the issue price, which is identified by using selected certificates. Our results indicate negative relationship between the barrier level (variants BROC1-BROC3; CRBOC1-CRBOC5) and the cap level (variants CRBOC1CRBOC3; CRBOC5-CRBOC7) on both certificates price, i.e. the higher the barrier level (further from the actual spot price $S_{0}$ )/ the cap level (closer to the actual spot price $S_{0}$ ) is, the higher the issue prices are and vice versa. Also, there is observed a positive influence of the leverage on both certificates price, i.e. the higher the leverage is, the higher the issue prices are and vice versa, as it is shown in the Table 4.

Table 4

Parameters of Selected BROC and CBROC Certificates (In USD Per 1 Certificate) with the Maturity Date 17/07/2015

\begin{tabular}{|c|c|c|c|c|c|c|c|c|c|c|}
\hline \multicolumn{2}{|c|}{ Denotation } & $\begin{array}{c}\mathbf{B} \\
\text { (USD) }\end{array}$ & $\begin{array}{c}\mathbf{S}_{\mathbf{0}} \\
\text { (USD) }\end{array}$ & $\mathbf{p}\left(\mathbf{S}_{0}\right)$ & $\mathbf{c}\left(2 \mathrm{~S}_{0}\right)$ & $\mathbf{c}_{\mathrm{UO}}\left(\mathbf{S}_{0}\right)$ & $\begin{array}{c}\mathbf{C} \\
\text { (USD) }\end{array}$ & $\mathbf{p}(\mathbf{C})$ & $\mathbf{m}$ & $\begin{array}{c}\mathbf{k}_{0} \\
\text { (USD) }\end{array}$ \\
\hline \multirow{4}{*}{$\begin{array}{l}u \\
0 \\
\frac{1}{m}\end{array}$} & 1 & 30 & 28.61 & 2.62 & 0.01 & 1.26 & - & - & 2 & 32.50 \\
\hline & 2 & 30 & 28.61 & 2.62 & 0.01 & 1.26 & - & - & 3 & 35.11 \\
\hline & 3 & 32 & 28.61 & 2.62 & 0.01 & 2.15 & - & - & 2 & 33.39 \\
\hline & 4 & 32 & 28.61 & 2.62 & 0.01 & 2.15 & - & - & 3 & 36.01 \\
\hline \multirow{8}{*}{$\begin{array}{l}0 \\
\frac{1}{0} \\
0\end{array}$} & 1 & 30 & 28.61 & 2.62 & 0.01 & 1.26 & 26 & 1.53 & 2 & 29.45 \\
\hline & 2 & 30 & 28.61 & 2.62 & 0.01 & 1.26 & 26 & 1.53 & 3 & 30.54 \\
\hline & 3 & 30 & 28.61 & 2.62 & 0.01 & 1.26 & 24 & 0.95 & 2 & 30.60 \\
\hline & 4 & 30 & 28.61 & 2.62 & 0.01 & 1.26 & 24 & 0.95 & 3 & 32.26 \\
\hline & 5 & 32 & 28.61 & 2.62 & 0.01 & 2.15 & 26 & 1.53 & 2 & 30.34 \\
\hline & 6 & 32 & 28.61 & 2.62 & 0.01 & 2.15 & 26 & 1.53 & 3 & 31.44 \\
\hline & 7 & 32 & 28.61 & 2.62 & 0.01 & 2.15 & 24 & 0.95 & 2 & 31.49 \\
\hline & 8 & 32 & 28.61 & 2.62 & 0.01 & 2.15 & 24 & 0.95 & 3 & 33.16 \\
\hline
\end{tabular}

Notes: BROC barrier reverse outperformance certificate, CBROC capped barrier reverse outperformance certificate, B barrier level, $S_{0}$ actual price, $p$ put option, $c$ call option, $c_{U O}$ up and knock-out call option, $C$ cap level, $m$ leverage, $k_{0}$ issue price

\section{Empirical Results of the Profitability Analysis}

Now let's consider designed certificates with the barrier level 32.00 USD, the leverage 2 and for capped certificate, the cap level is 26.00 USD. Profit profile of BROC is based on relation (13) and CBROC on relation (14). We compare these certificates with reverse linear certificate (referred to as RLC henceforth), which replicate inversely UA. RLC is created as a sum of BNO selling with the price 28.61 USD and the buying of call option in BNO with the strike level 57.22 USD, option premium

a) Barrier level is not broken during time to maturity

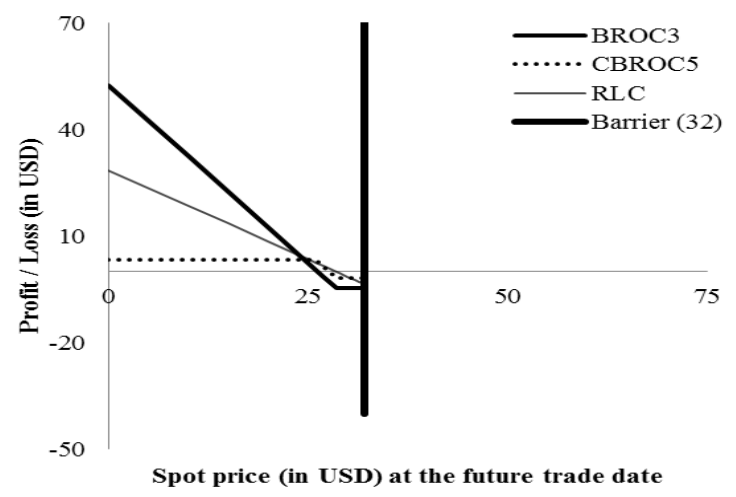

0.01 USD for an option, the expiration date $17^{\text {th }}$ July 2015 . Profit profile is represented by equation

$$
P\left(S_{t}\right)= \begin{cases}28.60-S_{t} & \text { if } S_{t}<28.61, \\ -28.62 & \text { if } S_{t} \geq 57.22\end{cases}
$$

The comparison of the profit from designed BROC, CBROC and RLC on BNO with the barrier level 32.00 USD, the leverage 2 and the cap level 26.00 USD depending on BNO price performance at the future trade date $t$ of the certificates (if the barrier level is not (left figure)/ is (right figure) broken during time to maturity) is illustrated in the Figure 1.

b) Barrier level is broken during time to maturity

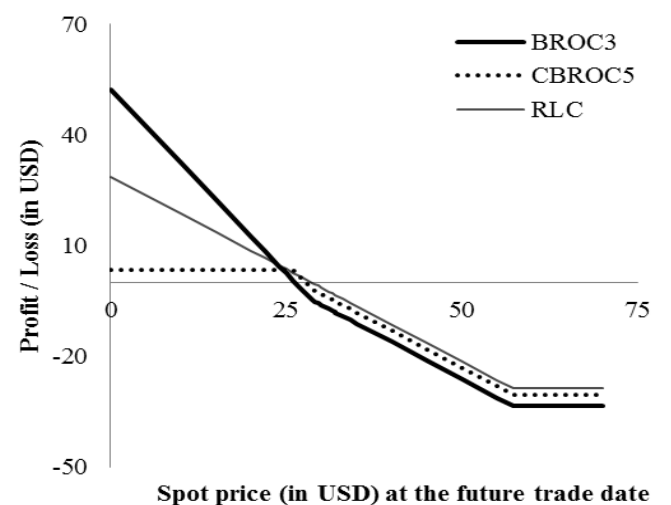

Figure 1. Profit/Loss (In USD Per 1 Certificate) from the Proposed BROC, CBROC and RLC at the Future Trade Date 
The analysed results (Figure 1) indicate that all three certificates may generate the maximum profit. However in the real world, there is impossible of BNO price drop at zero, when the maximum profit of 52.44 USD per certificate can be gained. The certificate's profitability depends on the achievement of the barrier level or not. If the BNO price at the future trade date drops under 23.84 USD (it does not matter if the barrier level is or not broken), i.e. from interval $(0 ; 23.84)$, then BROC3 ensures the highest profit, which is connected with the higher loss for unfavourable BNO price performance from interval $(25.11 ; \infty)$ in comparison to others certificates. If the barrier is not broken during certificate's lifetime and the BNO price is in interval $(23.84 ; 25.11)$, RLC certificate is the better as others certificates. If the BNO price is from interval $(25.11 ; 32.00)$, CRBOC5 certificate appears as the better certificate for investors. In case of achievement of the barrier level during time to maturity (the security buffer is cancelled) and the BNO price at the future trade date is above 23.84 USD, then the loss of all certificates is increased proportional with the higher the $\mathrm{BNO}$ price (the best variant RLC), however the limitation of loss is determined by buying certificate's price.

Finally, there is evaluated the profitability analysis of given certificates from investor's point of view. We expect some percentage change of UA's price with comparison to the actual spot price. The results are shown in the Table 5 with the finding of the best certificate for potential investor according to his/her expectation.

In the Table 5 we can see, that if the BNO price is at the level of the actual price $0 \%$ (28.61 USD), investor make a loss from the given certificates, the highest in case of BROC3. The security buffer is a reason the higher issue price of the certificates. Although these new products appear as a profitable investment, it is not always true. It depends on the right positioning of the given parameters. Therefore, the investor makes a profit if the BNO price decreases about $10 \%$ from the actual price for BROC 3 and in case of CBROC5 about $5 \%$. For all certificates there is valid if the BNO price increases more than $100 \%$, investor suffer a total investment loss.

Table 5

Comparison of the Investor's P/L (in USD/per 1 Certificate) of new Barrier Outperformance Certificates on Different Percentage Changes of BNO at the Future trade date $t$

\begin{tabular}{|c|c|c|c|c|c|}
\hline \multirow{2}{*}{$\begin{array}{l}\% \text { change of } \mathrm{BNO} \\
\text { in comparison to } \\
\text { actual price }\end{array}$} & \multicolumn{2}{|c|}{ BROC3 } & \multicolumn{2}{|c|}{ CBROC5 } & \multirow{2}{*}{$\begin{array}{c}\text { RLC } \\
(\mathrm{P} / \mathrm{L} \text { in USD) }\end{array}$} \\
\hline & $\begin{array}{c}\mathrm{P} / \mathrm{L} \text { (in USD) if } \mathrm{B} \text { is } \\
\text { not breached }\end{array}$ & $\begin{array}{c}\mathrm{P} / \mathrm{L} \text { (in USD) if } \mathrm{B} \text { is } \\
\text { breached }\end{array}$ & $\begin{array}{c}\mathrm{P} / \mathrm{L} \text { (in USD) if } \mathrm{B} \text { is } \\
\text { not breached }\end{array}$ & $\begin{array}{c}\mathrm{P} / \mathrm{L} \text { (in USD) if } \mathrm{B} \text { is } \\
\text { breached }\end{array}$ & \\
\hline$-50 \%$ & 23.83 & 23.83 & 3.49 & 3.49 & 14.30 \\
\hline$-30 \%$ & 12.38 & 12.38 & 3.49 & 3.49 & 8.57 \\
\hline $15 \%$ & 3.80 & 3.80 & 3.49 & 3.49 & 4.28 \\
\hline$-10 \%$ & 0.94 & 0.94 & 3.49 & 3.49 & 2.85 \\
\hline$-5 \%$ & -1.92 & -1.92 & 1.13 & 1.13 & 1.42 \\
\hline $0 \%$ & -4.78 & -4.78 & -1.73 & -1.73 & -0.01 \\
\hline $5 \%$ & -4.78 & -6.21 & -1.73 & -3.16 & -1.44 \\
\hline $10 \%$ & -4.78 & -7.64 & -1.73 & -4.59 & -2.87 \\
\hline $15 \%$ & -9.08 & -9.08 & -6.03 & -6.03 & -4.30 \\
\hline $30 \%$ & -13.37 & -13.37 & -10.32 & -10.32 & -8.59 \\
\hline $50 \%$ & -19.09 & -19.09 & -16.04 & -16.04 & -14.32 \\
\hline $100 \%$ & -33.39 & -33.39 & -30.34 & -30.34 & -28.62 \\
\hline $120 \%$ & -33.39 & -33.39 & -30.34 & -30.34 & -28.62 \\
\hline
\end{tabular}

Notes: BROC barrier reverse outperformance certificate, CBROC capped barrier reverse outperformance, RLC reverse linear certificate, $P / L$ profit/loss, B barrier level

According to the performed analysis with the comparison of designed investment certificates, the following findings are presented. If there is expected rapid drop in the BNO price, but not excluded slow increase up to the barrier level, the best chosen certificates are without the cap level and with the higher level of the leverage. However, if it is predicted only slow drop in BNO price, but not expected achievement of the barrier level, then capped certificates are recommended for the investment. If it is broken the barrier level during time to maturity with slow movement around the actual spot price of BNO, then RLC is better opportunity for investors due to the lower buying price. Conclusions of our analysis indicate, that the lower cap levels of investment certificates, i.e. further to the actual spot price, are more expensive as to the higher cap levels, which are set closer to the actual spot price. Generally, in the case of certificates without cap it is possible to participate longer on the BNO price drop as in the case of capped certificates. Therefore, the most important role in investor's choice is given by the selection of investment certificates based on the appropriate parameters and expectations of the future UA's price performance.

\section{Conclusions}

The paper is aimed on the investment certificate's segment with the proposal of new barrier outperformance certificates creation using the analytical expression of vanilla and barrier options. In order we could design new modified outperformance certificates, it was necessary to introduce the review of the literature dealing with the issue of the structured products. When we provided the theoretical background of the structured products, on which our research analysis is performed, we can propose capped/ barrier reverse outperformance certificates. New barrier reverse outperformance certificates are suitable for moderately risky investors in bear markets with using the security buffer in case of increasing markets up to the barrier level. Based on the existing empirical studies of 
financial engineering, the paper's research problem is to prove the nature of these investment modifications' creation based on the option pricing models in oil market. Creation of these products is demonstrated using option strategies with finding the best variants of the certificates according to the choosing of suitable input parameters.

Our empirical approach is applied on the United States Brent Oil ETF. As a result, several certificates on the United States Brent Oil ETF with different parameters are created, analysed and compared with their profitability investigation. There are presented alternative investments using American-style of vanilla and barrier option prices from $1^{\text {st }}$ December 2014. American real vanilla option prices are obtained from Bloomberg. Due to lack of American barrier options we calculate their prices according to Haug option pricing models in Bloomberg. By means of the selection of the most important features, it has been sought to discover, which factors influence on the price of capped/ barrier reverse outperformance certificates.

Generally, investment certificates are financial derivatives, which involve more complex structures. They are created using different components with the implementation of certain option strategies. Our approach of the investment certificates creation is based on using the alternative investment's profit profiles in the analytical expression. The main aim is to prove the nature of these products' creation using option strategies with the increasing of the intellectualization of all potential investors in Europe.

From the methodological aspect, our research can be provided as an inspiration for other types of the certificates' creation, for example with using of European options and any underlying assets, such as stocks, indices, currencies etc.

\section{References}

Baule, R., \& Tallau, C. (2011). The pricing of path-dependent structured financial retail products: The case of bonus certificates. The Journal of Derivatives, 18(4), 54-71.

Benet, B. A., Giannetti, A., \& Pissaris, S. (2006). Gains from structured product markets: The case of reverseexchangeable securities (RES). Journal of Banking \& Finance, 30(1), 111-132.

Black, F., \& Scholes, M. (1973). Pricing of Options and the Corporate Liabilities. Journal of Political Economy, 81(3), $637-654$.

Black, F. (1976). The pricing of Commodity Contracts. Journal of Financial Economics, 3(1/2), 167-179.

Bluemke, A. (2009). How to invest in structured products: a guide for investors and investment advisors. Chippenham: Wiley.

Bobrikova, M., \& Harcarikova, M. (2015). Reverse bonus certificate design and valuation using pricing by duplication methods. Scientific Annals of the "Alexandru Ioan Cuza" University of Iasi. Economic Sciences, 62(3), 277-289.

Breuer, W., \& Perst, A. (2007). Retail banking and behavioral financial engineering: The case of structured products. Journal of Banking \& Finance, 31(3), 827-844.

Boyle, P. P., \& Lau, S. H. (1994). Bumping up against the barrier with the binomial method. The Journal of Derivatives, $1(4), 6-14$.

Burth, S., Kraus, T., \& Wohlwend, H. (2001). The pricing of structured products in the Swiss market. The Journal of Derivatives, 9(2), 30-40.

Das, S. R., \& Statman, M. (2013). Options and structured products in behavioral portfolios. Journal of Economic Dynamics and Control, 37(1), 137-153.

Entrop, O., Scholz, H., \& Wilkens, M. (2009). The price-setting behavior of banks: An analysis of open-end leverage certificates on the German market. Journal of Banking \& Finance, 33(5), 874-882.

Garman, M. B., \& Kohlhagen, S. W. (1983). Foreign currency option values. Journal of International Money and Finance, 2(3), 231-237.

Geman, H. (2005). Commodities and Commodity derivatives: Modeling and Pricing for Agriculturals, Metals and Energy. United Kingdom: Wiley.

Gordiakova, Z., \& Younis, A. M. A. (2013). Proposal of a new guaranteed certificate using exotic options. Journal of Applied Economic Sciences, 8(2), 191-197.

Grunbichler, A., \& Wohlwend, H. (2005). The valuation of structured products: empirical findings for the Swiss market. Financial Markets and Portfolio Management, 19(4), 361-380.

Harcarikova, M. (2015). Proposal of new outperformance certificates in agricultural market. Agricultural Economics (Czech Republic), 61(9), 400-409.

Haug, E. G. (1997). The Complete Guide to Option Pricing Formulas. London: McGraw-Hill.

Haug, E. G. (1999). Closed form valuation of american barrier options. Working Paper, Derivatives Research, Tempus Financial Engineering, Norway.

Henderson, B. J., \& Pearson, N. D. (2011). The dark side of financial innovation: A case study of the pricing of a retail financial product. Journal of Financial Economics, 100(2), 227-247. 
Hernandez, R., Jones, J., \& Gu, Y. (2011). An economic analysis of protect certificates - An option-pricing approach. Banking and Finance Review, 3(2), 17-40.

Hernandez, R., Lee, W. Y., Liu, P., \& Dai, T. S. (2013). Outperformance Certificates: analysis, pricing, interpretation, and performance. Review of Quantitative Finance and Accounting, 40(4), 691-713.

Hernandez, R., Jones, J. S., \& Gu, J. (2014). Protect Put Certificates-a Case of Bearish Structured Products. American Journal of Business Research, 7(1), 61-79.

Hull, J. C. (2012). Options, Futures and Other Derivatives. New Jersey: Prentice-Hall.

Choudhry, M. (2004). Corporate bonds and structured financial products. Oxford: Elsevier Butterworth-Heinemann.

Merton, R. C. (1973). Theory of rational option pricing. Journal of Economics and Management Science, 4(1), $141-183$.

Nishiba, M. (2013). Pricing Exotic Options and American Options: A Multidimensional Asymptotic Expansion Approach. Asia-Pacific Financial Markets, 20(2), 147-182.

Ramaswamy, K., \& Sundaresan, S. M. (1985). The Valuation of Options on Futures Contracts. Journal of Finance, 40(5), 1319-1340.

Rich, Don R. (1997). The mathematical foundations of barrier option pricing theory. Advances in futures and options research: a research annual, 7, 267-312.

Ritchen, P. (1994). On pricing barrier options. The Journal of Derivatives, 3(2), 19-28.

Rossetto, S., \& Bommel, J. (2009). Endless leverage certificates. Journal of Banking \& Finance, 33(8), $1543-1553$.

Rubinstein, M., \& Reiner, E. (1991). Breaking Down the Barriers. Journal of Risk, 4(8), 28-35.

Rusnakova, M., Gordiakova, Z., \& Harcarikova, M. (2014). Design principles of capped bonus and capped twin-win certificates. Ekonomski Pregled, 65(4), 352-382.

Rusnakova, M., \& Soltes, V. (2012). Long strangle strategy using barrier options and its application in hedging. Actual Problems of Economics, 134(8), 452-465.

Schroff, S., Meyer, S., \& Burghof H. P. (2016). Retail investor information demand - speculating and investing in structured products. European Journal of Finance, 22(11), 1063-1085.

Stoimenov, P. A., \& Wilkens, S. (2005). Are structured products 'fairly' priced? An analysis of the German market for equity-linked instruments. Journal of Banking \& Finance, 29(12), 2971-2993.

Soltes, M. (2010). Relationship of speed certificates and inverse vertical ratio call back spread option strategy. $E+M$ Ekonomie a Management, 13(2), 119-124.

Soltes, M. (2012). New Option Strategy and Its Using for Investment Certificate Issuing. In: Procedia Economics and Finance: Emerging Markets Queries in Finance and Business: EMFB 2012: 24-27 October 2012, Tirgu-Mures, Romania, 3(1), 199-203.

Soltes, V. (2001). Analysis of long condor strategy application with some proposals related to optimal algorithm in practical investment. Ekonomicky casopis, 49(2), 306-317.

Soltes, V. (2002). Financne derivaty. Kosice: EkF TUKE.

Soltes, V. (2011). The Application of the Long and Short Combo Option Strategies in the Building of Structured Products. In: Liberec Economic Forum 2011: proceedings of the 10th international conference: 19-20 September 2011, Liberec. Liberec: Technical University of Liberec, 481-487.

Soltes, V., \& Rusnakova, M. (2012). Long Combo strategy using barrier options and its application in hedging against a price drop. Acta Montanistica Slovaca, 17(1), 17-32.

Soltes, V., \& Rusnakova, M. (2013). Hedging Against a Price Drop Using the Inverse Vertical Ratio Put Spread Strategy Formed by Barrier Options. Inzinerine Ekonomika-Engineering Economics, 24(1), 18-27.

Taleb, N. (1997). Dynamic hedging. Managing vanilla and exotic options. Hardcover: Wiley \& Sons.

Tauser, J., \& Cajka R. (2014). Hedging techniques in commodity risk management. Agricultural Economics (Czech Republic), 60(4), 174-182.

Wallmeier, M., \& Diethelm, M. (2009). Market Pricing of Exotic Structured Products: The Case of Multi-Asset Barrier Reverse Convertibles in Switzerland. Journal of Derivatives, 17(2), 59-72.

Wilkens, S., Erner, C., \& Roder, K. (2003). The pricing of structured products in Germany. The Journal of Derivatives, 11(1), 55-69.

Wilkens, S., \& Stoimenov, P. A. (2007). The pricing of leverage products: An empirical investigation of the German market for 'long' and 'short' stock index certificates. Journal of Banking \& Finance, 31(3), 735-750.

Younis, A. M. A., \& Rusnakova, M. (2014). Formation of the new types of bonus certificates. Actual Problems of Economics, 152(2), 367-375.

Zhang, P. G. (1998). Exotic options. Singapore: World Scientific Publishing Co.Pte.Ltd.

The article has been reviewed.

Received in April, 2015; accepted in June, 2017. 